\title{
Review
}

\section{Carbohydrate components in sweetpotato storage roots: their diversities and genetic improvement}

\author{
Kanefumi Kitahara'), Yoshiyuki Nakamura $^{2)}$, Motoyasu Otani ${ }^{3)}$, Tatsuro Hamada ${ }^{3)}$, Osamu Nakayachi ${ }^{3)}$ \\ and Yasuhiro Takahata*4) \\ 1) Department of Food Science and Biotechnology, Faculty of Agriculture, Kagoshima University, 1-21-24 Korimoto, Kagoahima, \\ Kagoshima 890-0065, Japan \\ 2) Division of Field Crop Research, Institute of Crop Science, NARO, 2-1-2 Kannondai, Tsukuba, Ibaraki 305-8518, Japan \\ 3) Research Institute for Bioresources and Biotechnology, Ishikawa Prefectural University, Nonoichi, Ishikawa 921-8836, Japan \\ 4) Department of Planning, Kyushu Okinawa Agricultural Research Center, NARO, Suya 2421, Koshi, Kumamoto 861-1192, Japan
}

\begin{abstract}
Carbohydrates are important components in sweetpotatoes in terms of both their industrial use and eating quality. Although there has been a narrow range of diversity in the properties of sweetpotato starch, unique varieties and experimental lines with different starch traits have been produced recently both by conventional breeding and genetic engineering. The diversity in maltose content, free sugar composition and textural properties in sweetpotato cultivars is also important for their eating quality and processing of storage roots. In this review, we summarize the current status of research on and breeding for these important traits and discuss the future prospects for research in this area.
\end{abstract}

Key Words: sweetpotato, Ipomoea batatas, carbohydrate, starch, maltose, free sugar, texture.

\section{Introduction}

The sweetpotato (Ipomoea batatas (L.) Lam) is cultivated on about 8 million ha and about 110 million tons are harvested annually throughout the world (FAOSTAT 2015). Among ordinary crops, it ranked tenth in the world in 2013 in production in terms of both quantity and value. It is cultivated mainly in Asian and African countries, China in particular, where about $70 \%$ of worldwide production occurs (FAOSTAT 2015). In Japan, sweetpotato breeding has been carried out for more than 100 years, starting in 1914 when the method of cross-breeding for practical purposes was initiated (Kukimura et al. 1990). The storage root is used not only as a whole root for human and livestock consumption but also in manufactured products such as starch, spirits, and regional domestic products. Starch is a fundamental component in the storage roots of the sweetpotato and plays a significant role in various aspects of its utilization. The eating quality of the sweetpotato depends on its texture and sweetness, and the both of these qualities are largely based on the quantity and quality of carbohydrates (Walter et al. 1975, Walter 1987). In this review, we summarize the recent

Communicated by Kenji Katayama

Received August 17, 2016. Accepted October 31, 2016.

First Published Online in J-STAGE on February 16, 2017.

*Corresponding author (e-mail: ytaka@affrc.go.jp) progress and new findings in the research, including genetic engineering research, on the carbohydrate components in sweetpotato storage roots.

\section{Physicochemical properties of recent sweet-} potato starches in Japan

Starch is the most important carbohydrate component in the storage root of the sweetpotato. Of the many botanical starches, cereal starches such as those found in corn seeds generally have a smaller granular size, higher pasting temperature, and lower pasting viscosity. On the other hand, tuber starches such as those found in potato tubers grown underground generally have a larger granular size, lower pasting temperature, and higher pasting viscosity. The general properties of sweetpotato starch appear to take a middle position among the many starches (Suganuma et al. 1996). It appears that sweetpotatoes of the conventional varieties and early breeding varieties, as well as currently popular varieties in Japan, which were selected primarily based on their desirable agronomic characteristics, such as disease resistance and high and stable yield, have relatively similar starches in terms of their pasting properties, amylose content, phosphate content, and the chain-length distribution of the debranched starch (Kitahara et al. 1996a). However, during the course of exploring the properties of sweetpotato starch, a few unique starches exhibiting a low amylose 
content (Kitahara et al. 1996b), a moderately low gelatinization temperature (Kitahara et al. 1999), a very low gelatinization temperature (Katayama et al. 2002, 2003, 2004), and a somewhat high amylose content (Katayama et al. 2011) were discovered in Japan. Subsequently, sweetpotato breeding that is focused on the properties of starch has developed new superior varieties and diverse lines as genetic resources. One result of these efforts is that a ground-breaking variety for the manufacture of starch, 'Konamizuki' (KM), has been bred at the Kyushu Okinawa Agricultural Research Center, National Agriculture and Food Research Organization of Japan (KARC/NARO, Katayama et al. 2012). This variety is expected to provide a new starch material for foods, as the gelatinized starch shows slow retrogradation and desirable gel-forming properties.

Because a comprehensive review of the physicochemical properties of sweetpotato starches has recently been published (Zhu and Wang 2014), the present chapter in this review will focus on the starch properties of recently bred sweetpotatoes in Japan, including the KM variety. Moreover, we introduce a variety of technical books and reviews in order to elucidate some of the fundamental background to the structures and physical properties of starch (e.g. Ai and Jane 2015, BeMiller 2007, Bertoft 2013, Hizukuri et al. 2006, Pérez and Bertoft 2010, Vamadevan and Bertoft 2015).

\section{2-1. General properties of sweetpotato starches}

Table 1 summarizes the general properties of starches derived from recently developed sweetpotato varieties in Japan, including those of the leading cultivars, 'Koganesengan' and 'Kokei 14' (Kitahara et al. 2014). The pasting temperature determined using the Rapid Visco Analyzer (RVA) ranged from $58.4^{\circ} \mathrm{C}$ to $76.2^{\circ} \mathrm{C}$, and the gelatinization peak temperature determined using a differential scanning calorimeter ranged from $50.1{ }^{\circ} \mathrm{C}$ to $74.2^{\circ} \mathrm{C}$. The gelatinization enthalpy ranged from $12.9 \mathrm{~J} / \mathrm{g}$ to $16.1 \mathrm{~J} / \mathrm{g}$; two starches with low gelatinization temperatures, which were derived from the 'Quick Sweet' and KM varieties, also showed low gelatinization enthalpy values. Arguably, the use of these starches for industrial applications would save energy, as they gelatinize at low temperatures with low enthalpy. Some structural properties of the starches are also shown in Table 1. The apparent amylose contents of the starches ranged from $18.6 \%$ to $20.7 \%$ for the 'Koganesengan' and 'Okikogane' varieties, respectively, showing a narrow range of variation and values typical of as standard sweetpotato starches (Zhu and Wang 2014). The diversity of the amylose contents of Japanese sweetpotato starches appears to be low (11.3-25.3\%, Katayama et al. 2004, 2011, Kitahara et al. 1996b, Tokimura et al. 2002), although waxy starches have been found in root crops, such as potato (HovenkampHermelink et al. 1987), cassava (Ceballos et al. 2007), and yam (Pérez et al. 2011). Such waxy starches are expected to offer great potential for the food industry. In addition, the sweetpotato starches of the 'Quick Sweet' and KM varieties showed the common properties of a low phosphate content and B-type crystalline structure, as well as similar pasting and gelatinization properties. Thus, according to the pasting and gelatinization behaviors and structural properties, the sweetpotato starches in Japan were roughly divided into two groups: (1) starches with a low gelatinization temperature; and (2) the so-called standard sweetpotato starches. Recently, it was reported that the trait of having a low gelatinization temperature exhibited by sweetpotato starch is a qualitative characteristic controlled by a spt recessive allele and inherited in a hexasomic manner (Katayama et al. 2015). The sweetpotato starches with a low gelatinization temperature are unique to Japan at present.

Table 1. General properties of starches from recently bred sweetpotato cultivars in Japan

\begin{tabular}{|c|c|c|c|c|c|c|c|c|}
\hline Main use (Trait) & & $\begin{array}{l}\text { RVA pasting } \\
\text { temperature } \\
\quad\left({ }^{\circ} \mathrm{C}\right)\end{array}$ & $\begin{array}{l}\text { DSC peak } \\
\text { gelatinization } \\
\text { temperature } \\
\left({ }^{\circ} \mathrm{C}\right)\end{array}$ & $\begin{array}{l}\text { DSC gelatini- } \\
\text { zation } \\
\text { enthalpy } \\
(\mathrm{J} / \mathrm{g})\end{array}$ & $\begin{array}{l}\text { Apparent } \\
\text { amylose } \\
\text { content }(\%)\end{array}$ & $\begin{array}{l}\text { Attached } \\
\text { phosphate } \\
\text { content } \\
(\mu \mathrm{mol} / \mathrm{g})\end{array}$ & $\begin{array}{l}\text { Median } \\
\text { granular size } \\
\qquad(\mu \mathrm{m})\end{array}$ & $\begin{array}{l}\text { Crystalline } \\
\text { type }\end{array}$ \\
\hline \multicolumn{9}{|c|}{ Recently bred cultivars } \\
\hline Konahomare & $\begin{array}{l}\text { Starch production } \\
\text { (High yield, High starch) }\end{array}$ & 75.6 & 74.2 & 15.2 & 20.4 & 6.43 & 13.6 & $\mathrm{Ca}$ \\
\hline Daichinoyume & $\begin{array}{l}\text { Starch production } \\
\text { (High yield, High starch) }\end{array}$ & 74.7 & 70.1 & 15.1 & 19.3 & 3.51 & 14.8 & $\mathrm{Ca}$ \\
\hline Okikogane & $\begin{array}{l}\text { Food processing, Cooking } \\
\text { (Low starch, Low sweetness) }\end{array}$ & 74.9 & 73.2 & 14.8 & 20.7 & 5.59 & 14.1 & $\mathrm{Ca}$ \\
\hline Konamizuki & $\begin{array}{l}\text { Starch production } \\
\text { (High yield, High starch, Low } \\
\text { gelatinization temperature) }\end{array}$ & 58.4 & 52.2 & 13.1 & 19.9 & 1.27 & 17.6 & B \\
\hline Quick Sweet & $\begin{array}{l}\text { Vegetable use } \\
\text { (Low gelatinization temperature) }\end{array}$ & 58.8 & 50.1 & 12.9 & 20 & 1.17 & 14.3 & B \\
\hline \multicolumn{9}{|c|}{ Traditional bred cultivars } \\
\hline Koganesengan & $\begin{array}{l}\text { Leading cultivar for shochu production } \\
\text { (High yield, High starch, Good flavor) }\end{array}$ & 76.2 & 71.7 & 16.1 & 18.6 & 5.63 & 13.0 & $\mathrm{Ca}$ \\
\hline Kokei 14 & $\begin{array}{l}\text { Leading cultivar for vegetable use } \\
\text { (Good taste) }\end{array}$ & 75.6 & 71.9 & 14.9 & 19.3 & 4.61 & 12.8 & $\mathrm{Ca}$ \\
\hline
\end{tabular}

All measurements are conducted in accordance with the previous methods (Kitahara et al. 2014). 
2-2. Distinctive molecular structures of starch exhibiting a low gelatinization temperature

In general, sweetpotato starch has a diameter of $2-50 \mu \mathrm{m}$ and is bell-shaped, round, or polygonal shaped. Fig. 1 shows the morphological differences between the two types of sweetpotato starches, namely the standard sweetpotato starch and the unique sweetpotato starch exhibiting a low gelatinization temperature. Many larger granules with cracks at the center were observed in the KM starch than in the 'Konahomare' (KH) starch. The median granular sizes were $17.6 \mu \mathrm{m}$ and $13.6 \mu \mathrm{m}$ for the unique and standard starches, respectively (Table 1 ). Fig. 2 shows the chainlength distributions of the isolated amylopectins from $\mathrm{KH}$ and KM starches on two linked columns of Superose 6 10/300 GL and Superdex Peptide 10/300 GL (GE Healthcare Japan). We devised a convenient and useful method to compare number-based chain-length distributions between starches (Kitahara et al. 2014). In simple terms, each output of the refractive index detector through the weight-based chain length distribution was divided by each degree of polymerization (DP) value obtained from a calibration curve with commercial Pullulan standards (Shodex Standard P-82
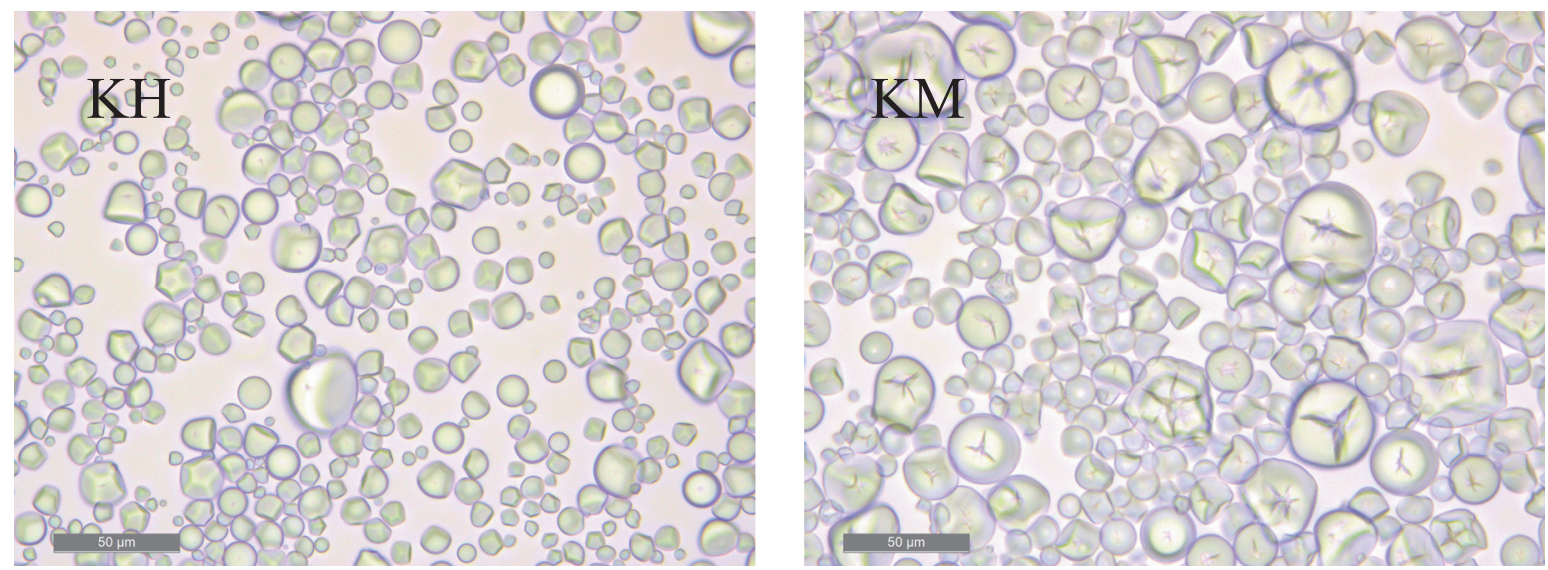

Fig. 1. Optical microphotographs of Konahomare (KH) and Konamizuki (KM) starch granules (Kitahara et al. 2014). Bars in the photographs represent $50 \mu \mathrm{m}$.

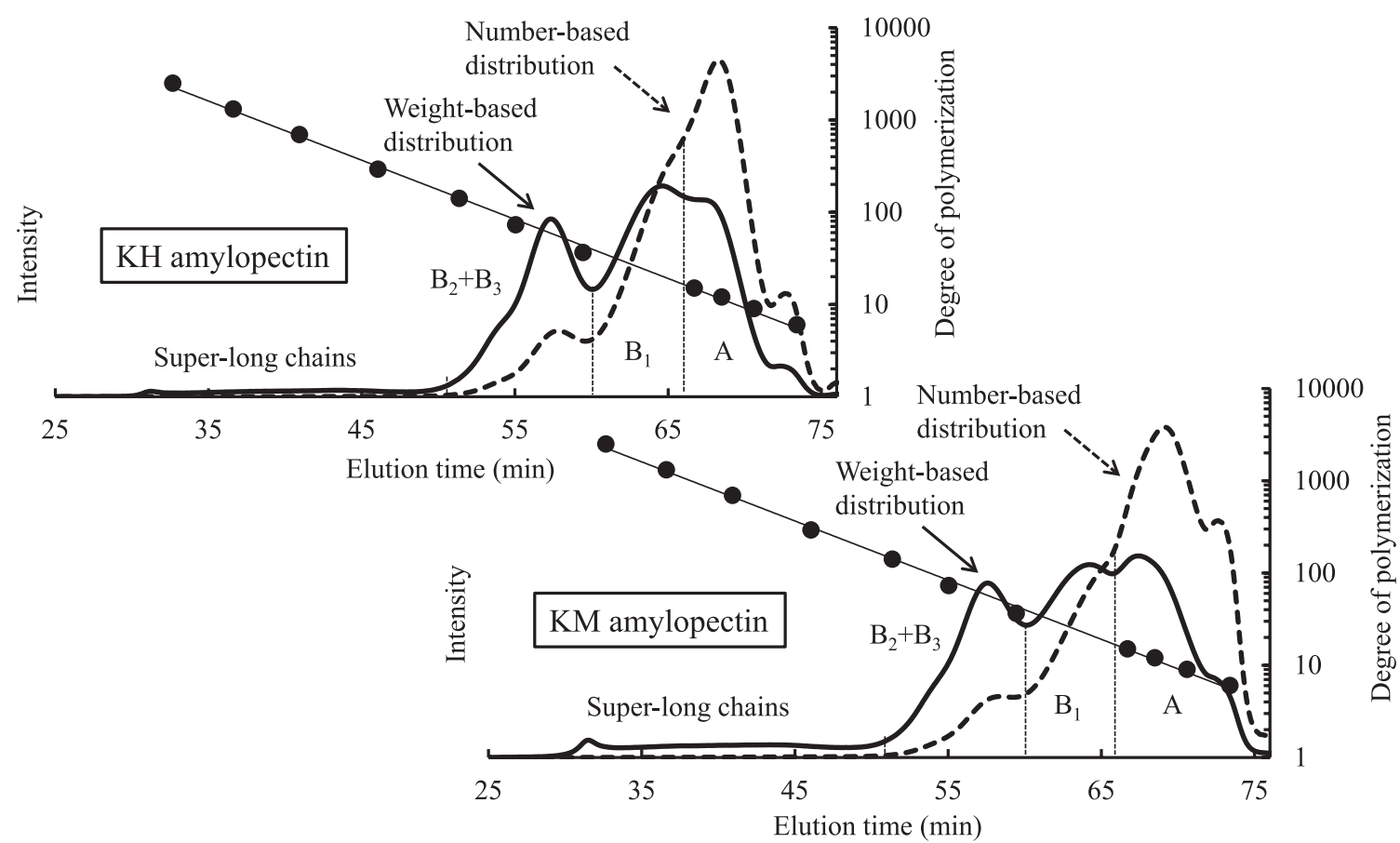

Fig. 2. Weight-based chain-length distributions determined by gel permeation chromatography with refractive index detection and their calculated number-based chain-length distributions of Konahomare (KH) and Konamizuki (KM) amylopectins (Kitahara et al. 2014). The solid line indicates the distribution of weight-based chain lengths, and the dotted line indicates the distribution of number-based chain lengths. Vertical dotted lines indicate the division of the distribution into unit-chain fractions of the cluster structure of amylopectin. Commercial pullulan standards (closed circle) with known DPs were used for the column system. 
and P2) at the retention time, providing the number-based chain-length distribution. This calculation was performed using the Microsoft Excel software. Following Hanashiro et al. (2002), the calculated number-based chain length distribution was divided into three fractions, $A, B_{1}$, and $B_{2}+B_{3}$, at inflection points. The molar amounts of the $A, B_{1}$, and $\mathrm{B}_{2}+\mathrm{B}_{3}$ fractions were estimated to be $61.7 \%, 28.4 \%$ and $9.7 \%$ for the $\mathrm{KH}$ amylopectin, and $69.4 \%, 22.5 \%$, and $7.9 \%$ for the KM amylopectin, respectively. The periodic distribution of the KM amylopectin showed a clearer difference from that of the KH amylopectin than did their weightbased chain length distributions. Compared with $\mathrm{KH}$ amylopectin, KM amylopectin had more A chains, in particular, as well as twice the number of short chains with DP 6-10 and fewer $\mathrm{B}_{1}$ chains; however, the numbers of $\mathrm{B}_{2}+\mathrm{B}_{3}$ chains were comparable between the $\mathrm{KH}$ and $\mathrm{KM}$ amylopectins. Because maltooligosaccharides with DP 6-10 do not readily crystallize into a double-helical configuration (Gidley and Bulpin 1987, Pfannemüller 1987), the short chains with DP 6-10 in KM amylopectin are scarcely involved in the crystalline structure of starch granules, and their form can be imagined as many downy hairs in a cluster of amylopectin molecules. Such short chains with DP 6-10 act as an unstable factor for maintaining the starch granules, resulting in the ease of gelatinization of starch granules. On the other hand, the hydrated short chains after gelatinization act to resist crystallization, resulting in a high water-holding ability and slow retrogradation. The abundance of short chains with DP 6-10 in amylopectin molecules accounts for the reduction in starch synthase II activity observed in major crops (Edwards et al. 1999, Lloyd et al. 1999, Morell et al. 2003, Nakamura et al. 2005, Umemoto et al. 2002, Yamamori et al. 2000, Zhang et al. 2004) including the sweetpotato (Takahata et al. 2010). Furthermore, amyloselike super-long chains eluted at 30-50 min were observed in both amylopectins. It was clear that KM amylopectin had a larger amount of the super-long chains than $\mathrm{KH}$ amylopectin. The super-long chains of KM amylopectin are considered to play the role of crosslinking between each molecule in the starch paste, and are probably responsible for their strong gel-forming ability.

In this chapter, the structural properties of two types of Japanese sweetpotato starches were outlined. In particular, the KM variety has desirable agronomic characteristics and is expected to offer a highly functional starch that can offer energy-saving gelatinization, slow retrogradation, and high enzyme-digestibility, for use in food materials (Katayama et al. 2012, Kitahara et al. 2014) or as a feedstock for bioethanol production (Srichuwong et al. 2012).

3. Development of starch metabolic pathway engineering in sweetpotato

Genetic engineering of the amylose content has great potential to improve the quality of sweetpotato starch for the development of new dietary and industrial applications.
Metabolic engineering of the starch pathway by genetic transformation has progressed in crops such as rice, potatoes, and maize. In the sweetpotato, starch metabolic engineering has been advanced by a number of Japanese scientists (Kimura et al. 2001, Otani et al. 2007, Shimada et al. 2006, Takahata et al. 2010).

The starch biosynthesis pathways from adenosine diphosphoglucose (ADP-glucose) are catalyzed by multiple enzymes. The enzyme granule-bound starch synthase I (GBSSI) is the key enzyme in the biosynthesis of amylose, whereas the soluble starch synthases (SS), the starch branching enzymes (SBEs) I and II (SBEI and SBEII), and the debranching enzymes (DBE) act in concert to produce amylopectin. In the potato, antisense inhibition of GBSSI and $S B E I I$ resulted in amylose-free starch and a moderate increase in the apparent amylose level up to $38 \%$ (Jobling et al. 1999, Visser et al. 1991), respectively. We had been succeeded in producing an amylose-free sweetpotato with co-suppression of the GBSSI gene via the introduction of GBSSI cDNA into the sweetpotato genome (Kimura et al. 2001). However, the production frequency of the expected amylose-free transformed plants obtained using the cosuppression method was very low. Furthermore, the amylose-free character obtained using antisense-RNA or co-suppression was not stable in the vegetative propagated progenies of the potato and sweetpotato. Therefore, the production of starches that were amylose-free and exhibited other starch characteristics by new metabolic engineering had been expected in sweetpotato.

The double-stranded RNA (dsRNA)-mediated interference (RNAi) method has been found to be effective for the genetic improvement of crops (Waterhouse et al. 1998). The genetic manipulation of key enzymes related to the starch biosynthesis pathway using the RNAi method might produce altered starches such as high-amylose, very-highamylose, and amylose-free starches in the sweetpotato. In the present chapter, we describe the modification of sweetpotato starch by using dsRNA of the sweetpotato GBSSI, $S B E I, S B E I I, S S I I, A G P \alpha 1$, and $A G P \beta 1 A$ genes.

\section{3-1. Transformation methods of sweetpotato}

To produce knock-down mutants by RNAi it is essential to establish a genetic transformation system in the sweetpotato. To date, several works on establishing genetic transformation in the sweetpotato have been reported. An Agrobacterium tumefaciens-mediated transformation method targeting the embryogenic callus (EC) might be reasonable and reliable in the sweetpotato. The most important point in establishing a transformation system of the sweetpotato must be the induction of competent cells such as ECs which possess high regeneration potential and the trait of fast growth. Our routine methods for the induction of ECs and for transformation have already been reported (Otani and Shimada 1996, Otani et al. 1998). We currently use binary vector pZH2B (Hajdukiewicz et al. 1994, Kuroda et al. 2010) for the Agrobacterium-mediated transformation of 
Table 2. Characteristics of transgenic plants transformed with dsRNA of starch biosynthesis genes of the sweetpotato

\begin{tabular}{|c|c|c|c|c|c|c|c|}
\hline Plant lines & Genes & $\begin{array}{c}\text { Growth } \\
\text { of aerial part }\end{array}$ & $\begin{array}{l}\text { Total fresh weight of } \\
\text { storage root per plant }{ }^{a}\end{array}$ & $\begin{array}{l}\text { Sprouting trait } \\
\text { of storage roots }\end{array}$ & $\begin{array}{l}\text { Starch } \\
\text { yield }^{a}\end{array}$ & $\begin{array}{c}\text { Amylose } \\
\text { content }(\%)^{b}\end{array}$ & Reference \\
\hline Kokei 14 & - & Normal & 100.0 & - & 100.0 & $10.25 \pm 0.4$ & - \\
\hline Kokei 14/GBSSI & $w x$ & Normal & 96.8 & late & 88.3 & 0 & Otani et al. 2007 \\
\hline Kokei 14/SBEII & $a e$ & Normal & 92.1 & late & 89.7 & $24.85 \pm 0.6$ & Shimada et al. 2006 \\
\hline White Star & - & Normal & 100.0 & - & 100.0 & nd & - \\
\hline White Star/SSII & $d u l$ & Normal & 87.1 & nd & 98.0 & nd & Takahata et al. 2010 \\
\hline
\end{tabular}

${ }^{a}$ Data are expressed as relative ratios compared to non-transgenic Kokei 14 or White Star as $100 \%$.

${ }^{b}$ Average \pm S.D. $(\mathrm{n}=3-5)$.

nd: not determined.

the sweetpotato because of the ease of cloning and because of its higher transformation efficiency (unpublished data).

\section{3-2. Genetic manipulation of starch properties in the sweetpotato}

3-2-1. GBSSI. The GBSSI, which catalyzes the formation of amylose, is one of the key enzymes in the biosynthesis of starch. Amylose-free or low-amylose starch was produced by the antisense GBSSI RNA method in potatoes (Kuipers et al. 1994a, 1994b, Visser et al. 1991) and rice (Shimada et al. 1993). However, the amylose-free character of potatoes achieved by antisense RNA-mediated inhibition was not completely stable, and the efficiency of the production of amylose-free plants was low (Kuipers et al. 1994a, 1994b). On the other hand, several transgenic plants with the dsRNA of IbGBSSI were obtained by Agrobacterium-mediated transformation at a high frequency. No morphological differences in whole plants were observed between nontransgenic 'Kokei 14' and transgenic plants with the dsRNA of IbGBSSI (Table 2). When storage root slices of the transgenic plants with the dsRNA of IbGBSSI and non-transgenic 'Kokei 14' plants were stained by an iodine solution, 28 of 38 transgenic lines showed a red-brown stain, while the other 10 lines showed a dark blue color similar to non-transgenic roots (Fig. 3). Consequently, $73.7 \%$ of these transgenic plants contained amylose-free starch. The amylose-free character of transgenic plants with the dsRNA of IbGBSSI was stable in transgenic sweetpotato plants through both vegetative propagation and sexual crossing (Fig. 3).

3-2-2. SBE. The SBE, 1,4- $\alpha$-D-glucan-6- $\alpha$-[1,4-glucan]transferase, is a key enzyme in starch biosynthesis. It acts on glucose polymers and catalyzes the excision and transfer of glucan chains to either similar or different glucan molecules (Hussain et al. 2003, Pan and Nelson 1984). The SBEs can be divided into two classes, SBEI and SBEII classes, with distinct structures and enzymatic properties (Martin and Smith 1995). SBEs of SBEI class prefer amylose as a substrate and transfers relatively longer glucan chains (up to DP 30, with the majority being DP 10-13) (Kuriki et al. 1997, Takeda et al. 1993). On the other hand, SBEs of the SBEII class prefer amylopectin as a substrate and transfer relatively shorter chains (DP 6-14) (Guan and Preiss 1993).

High amylose starches are more hard to be decomposed by $\alpha$-amylase (EC 3.2.1.1) than normal starches, resulting in

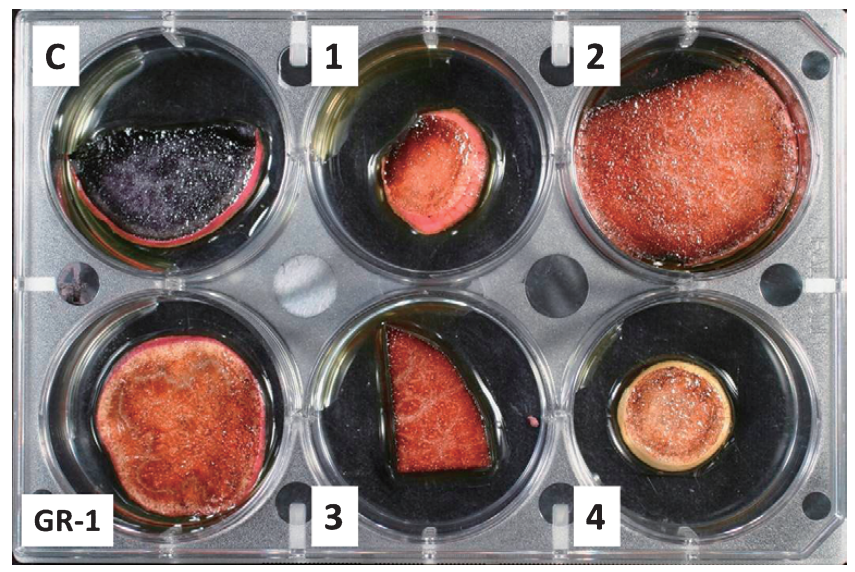

Fig. 3. Inheritance of the amylose-free character of storage roots of transgenic sweetpotatoes by sexual crossing (Otani et al. 2007). C: non-transgenic Kokei 14' plant, GR-1: transgenic amylose-free plant line with dsRNA of IbGBSSI. 1-4: progenies of GR-1 crossed with cv. 'Chikei 682-11'.

low digestibility (Tetlow 2011). High amylose starches showed several functional effects for health benefits such as lower postprandial glucose response (Nestel et al. 1996) and reduced energy due to its low caloric value (Brown 2004). Therefore, foods containing high amylose starches are beneficial for the human health. Transgenic potato and wheat with high-amylose levels were produced by antisense RNAs and RNAi for $S B E$ genes, respectively (Regina et al. 2006, Schwall et al. 2000). To produce high-amylose sweetpotatoes, dsRNAs of IbSBEII was expressed in transgenic sweetpotato plants (Shimada et al. 2006). The gene expression levels of endogenous $I b S B E I I$ were decreased in the storage roots of the transgenic plants. In the IbSBEII dsRNA transgenic plants, the amylose content in storage roots increased to $242.4 \%$, when compared with the control plant (Table 2). On the other hand, starch yield in the storage root of IbSBEII dsRNA transgenic plant was decreased slightly $(89.7 \%)$ when compared with the control plant (Table 2). Morphological differences in the aerial part and storage roots of the IbSBEII dsRNA transgenic plants were small (Table 2). Harvested storage roots showed very slow sprouting compared to those of non-transgenic 'Kokei 14', which was similar to the storage roots of transgenic plants with the dsRNA of IbGBSSI. Production and characterization of 
transgenic sweetpotatoes in which dsRNAs of $I b S B E I$ and $I b S B E S(I b S B E I+I I)$ are expressed is now in progress.

3-2-3. SSII. The activity of isoform II of SS (SSII) was considered to be a critical factor in the changes to the structure of starch granules and the low-temperature pasting property. Thus, the production of transgenic sweetpotato plants having low-pasting-temperature starch was believed to be caused by the dsRNA of IbSSII-mediated gene silencing.

Several transgenic plants with the dsRNA of IbSSII were obtained by Agrobacterium-mediated transformation (Takahata et al. 2010). No morphological differences in the aerial part or the storage roots were observed between nontransgenic 'White Star' and transgenic plants, although total fresh weight of the storage roots had been decreased slightly (Table 2). All of the starches from transgenic plants with the dsRNA of IbSSII showed lower pasting temperatures and breakdown. The pasting temperatures in transgenic plants were approximately $10-15^{\circ} \mathrm{C}$ lower than in non-transgenic 'White Star' plants. Further physicochemical properties of transgenic plants were examined and it was found that the starches of transgenic plants showed slower retrogradation and higher digestibitlity (Kitahara et al. 2011). Those properties of starches from transgenic plants with the dsRNA of IbSSII should lead to benefits not only in the table use of these plants but also in food industry applications and biofuel production. Thus, the knock-down trait of IbSSII should be combined with other starch biosynthesis-related genes to produce unique and useful starches.

3-2-4. AGPase. ADP-glucose pyrophosphorylase, EC 2.7.7.27 (AGPase), is an enzyme that catalyzes the reaction in which ADP-glucose and pyrophosphate are made from glucose-1-phosphate and ATP. ADP-glucose is the only or most important precursor for plant starch synthesis, and AGPase is thought to be the key enzyme in this biosynthetic pathway (Martin and Smith 1995, Preiss 1996). Most plant AGPases are tetramers consisting of two $\alpha$-subunits and two $\beta$-subunits (Preiss 1996). The genes of these subunits are referred to as Brittle2 and Shrunken2, respectively, and recessive mutants of these genes contain more sugars than wild Zea mays strains (Hannah and Nelson 1975, 1976). Production and characterization of transgenic sweetpotatoes in which dsRNAs of IbAGP $\alpha 1$ (IbAGPS) and IbAGP $\beta 1 A$ $(I b A G P L)$ are expressed are now in progress

3-2-5. ISA. Isoamylases (ISAs) are DBEs that cut the $\alpha-1$, 6-glycosidic bond in starch (Nakamura 1996). These enzymes are thought to contribute to the trimming of starch. Three isoforms are known to occur in plants. The gene of ISAI, one of these isoforms, is called Sugary1, and the recessive mutant of this gene contains more sugars than wild Z. mays strains. Several transgenic plants with the dsRNA of IbISAI, IbISAII or IbISAIII were regenerated, and the investigation of the morphological and physicochemical properties of these transgenic plants is in progress.
4. Starch, free sugars and other carbohydrates associated with sweetness and texture of cooked sweetpotato cultivars

Sweetpotatoes are used as food, forage, and ingredient in processed food and industrial products, in which they are often included in the form of starch. In Japan, approximately half of all sweetpotatoes produced, about 0.45 million tons, are sold in fresh markets; the eating quality of sweetpotato as well as its physiological functions such as antioxidant activity have attracted a great deal of attention. The eating quality of sweetpotato practically depends on its texture and sweetness, and both of these qualities are largely dependent on the quantity and quality of carbohydrates contained in the sweetpotato (Walter et al. 1975, Walter 1987). In this chapter, the starch and free sugar characteristics associated with the sweetness and texture of steamed storage roots of sweetpotato cultivars are described.

\section{4-1. Diversity in maltose content is associated with the sweetness of cooked sweetpotato cultivars}

The free sugars that predominantly existed in the storage roots of sweetpotatoes are fructose, glucose, sucrose, and maltose (Picha 1986a). Among these, maltose is hardly detected in raw fresh storage roots, and the other three sugars are presented in both raw and cooked storage roots. Takahata et al. (1992) classified the genotypes of sweetpotato cultivars and breeding lines into three groups based on the free sugar composition of their steamed storage roots. Group 1 consisted of cultivars and lines that contain a large amount of maltose in their steamed roots. Group 2 consisted of species that generate a small amount of maltose via steaming. The breeding lines that contain relatively large amounts of fructose and glucose were classified as group 3. The cultivars and lines belonging to group 1 show high $\beta$-amylase activity, while those belonging to group 2 are completely or mostly lacking this enzyme activity.

The storage roots of current Japanese sweetpotato cultivars suitable for table use contain 10 to $25 \%$ (w/w) starch, which is the largest constituent of the solid component of sweetpotato storage roots. In the cooking process, starch is gelatinized and then partially dissolved by two kinds of amylolytic enzymes, i.e. $\alpha$ - and $\beta$-amylase, to generate a large amount of maltose (Morrison et al. 1993). Maltose is the sugar highest in content among the four free sugars, namely fructose, glucose, sucrose, and maltose, that are mainly detected in cooked storage roots of ordinary sweetpotato cultivars. Although maltose has less than half of the sweetness of the other three sugars, it is mainly responsible for the sweetness of the cooked storage root of ordinary sweetpotato cultivars, which in this context refers to cultivars having $\beta$-amylase activity, because of its 10-times-higher concentration of maltose in comparison to the other sugars. The maltose concentration in steamed storage roots increased to a peak of approximately $10 \%(\mathrm{w} / \mathrm{w})$, with the enzymic activity increasing up to about $0.2 \mathrm{mmol}$ maltose $/ \mathrm{mg}$ protein 
of enzyme solution/min, and however, the maltose concentration did not increase with increasing activity if it increased to a level above $0.2 \mathrm{mmol}$ maltose $/ \mathrm{mg} / \mathrm{min}$ (Nakamura et al. 2014b). This result suggests that the activity of $\beta$-amylase in storage root is not the only definitive factor in the generation of maltose by cooking with heat in the sweetpotato.

One of the other limiting factors in maltose generation would be starch gelatinization. Starch gelatinization is a prerequisite for maltose generation by $\beta$-amylase because the enzyme of the sweetpotato is not able to attack raw (not gelatinized) starch granules (Ito et al. 1968). Starch gelatinization properties are characterized by various physicochemical phenomena such as thermal reaction, structural transition, and temperature-dependent changes in the viscosity of the starch suspension (Biliaderis 2009). The starch pasting temperature, the temperature at which the increase in viscosity of starch suspension is recognized for the first time during a temperature increase, is an index of the facility of starch gelatinization. The pasting or gelatinization temperature of isolated starch from sweetpotato storage roots is closely correlated with the distribution ratio of the chainlength of branch glucose in amylopectin molecules (Noda et $a l$. 1998). The increase in the distribution ratio of the shorter chain (DP 6-10) in sweetpotato amylopectin caused a distinct reduction of the gelatinization and pasting temperature of starch determined by differential scanning calorimetry (DSC) and RVA, respectively. It is also well known that the temperature during the growth period of the sweetpotato greatly affects the amylopectin structure and the resulting gelatinization or pasting properties of sweetpotato starch (Noda et al. 2001). The pasting temperature measured by RVA using a $7 \%(\mathrm{w} / \mathrm{w})$ suspension of isolated starch ranges from $50^{\circ} \mathrm{C}$ to $75^{\circ} \mathrm{C}$ for sweetpotato cultivars and breeding lines (Katayama et al. 2015). The cultivars and breeding lines with lower pasting temperatures are able to generate a larger amount of maltose than those with higher pasting temperatures if the cultivars and lines are similar in terms of $\beta$-amylase activity. The maltose concentration in the steamed storage roots of sweetpotato cultivars with $\beta$-amylase activity was negatively correlated with pasting temperature as measured by RVA using isolated starch (Nakamura et al. 2014b). 'Quick Sweet', developed at the beginning of $21^{\text {st }}$ century, was the first sweetpotato cultivar having unique starch gelatinization characteristics: its pasting temperature was around $55^{\circ} \mathrm{C}$, which was approximately $20^{\circ} \mathrm{C}$ lower than those of other ordinary cultivars (Katayama et al. 2002, 2003, 2004). Consequently, this cultivar was able to begin maltose generation at about a $20^{\circ} \mathrm{C}$ lower temperature than 'Beniazuma', which contains normal starch and whose pasting temperature is ca. $75^{\circ} \mathrm{C}$. Also, the maltose concentration in steamed storage roots of 'Quick Sweet' was about $40 \%$ higher than that in 'Beniazuma' (Nakamura et al. 2014a). The deterioration of the starch pasting temperature is associated with the inhibition of the expression of the starch synthase II gene (Takahata et al. 2010) and is qualitatively regulated by the dosage of recessive alleles (Katayama et al. 2015). The maltose generation in 'Quick Sweet' would continue at temperatures over $90^{\circ} \mathrm{C}$ because its $\beta$-amylase activity maintains a sufficient level despite the serious inhibition of this enzyme activity in 'Beniazuma'. Takahata et al. (1994) reported that the heat stability of $\beta$-amylase and the gelatinization of starch granules play an important role in high maltose generation. The development of new cultivars having low starch pasting temperatures such as 'Quick Sweet' continues to progress because they are effective for increasing the processability and functionality of the sweetpotato or its starch (Katayama et al. 2012, Kuranouchi et al. 2012).

As for the group 2, two cultivars, 'Satsumahikari' and 'Okikogane' were developed in the past 30 years (Baba et al. 1987). They do not produce practical amount of maltose as a result of heating due to a complete lack of or to having only traces of $\beta$-amylase activity in their storage roots. The trait of an absence of or an extremely low level of $\beta$ amylase activity is believed to be inherited easily because this genetic mutation is brought on by only a single recessive allele in their germplasm (Kumagai et al.1990). Such types of genetic variation will raise the potential of the sweetpotato as a crop for food and other uses.

\section{4-2. Other free sugars}

The other three sugars, namely fructose, glucose, and sucrose, are contained in both raw and cooked storage roots. The contents of these sugars do not show any significant changes after cooking; however, they show remarkable changes in raw storage roots during storage. Generally speaking, the sucrose content in raw storage roots of sweetpotatoes gradually increases together with a decrease in the starch content during storage (Picha 1986b), and lowering the storage temperature stimulates these changes (Picha 1987). The changes in the activity of sucrose-metabolizing enzymes such as sucrose synthase and sucrose phosphate synthase during storage have been extensively reported for potatoes, but few reports have been published on this topic in sweetpotato (Masuda et al. 2007, Takahata et al. 1995). The contents of fructose and glucose are highly correlated with the activity of acid invertase, which catalyze the conversion of sucrose into fructose and glucose (Takahata et al. 1996). Although the two sugars are known to have a close relationship to the quality of potatoes after storage (Matsuura-Endo et al. 2004, 2006), their role in the eating quality of sweetpotatoes remains to be investigated.

\section{4-3. Textural characteristics}

Another important factor in determining the eating quality of baked or steamed sweetpotato storage roots is their textural character, which consists of two major types, i.e. mealy and soggy. In the current breeding system in Japan, the textural character of a cultivar or breeding line is sensually determined after cooking by comparison with the textural character of the standard cultivar ('Kokei-14') and 
the character is sorted into five categories: mealy, slightly mealy, intermediate, slightly soggy, and soggy. "Intermediate" means that the texture is almost equal to the texture of the standard cultivar. This sensory evaluation system has some problems; for example, the texture of the standard cultivar often differs between harvest locations or from year to year, and the tasting peculiarity of the panel members is liable to influence the evaluation results. Therefore, the relationships between the textural character of the sweetpotato and the physicochemical properties of its constituents need to be determined to establish an invariant evaluation system of the texture of the sweetpotato. The most primary constituent associated with the texture of sweetpotato storage roots is starch. The concentration of starch presented in raw fresh storage roots is generally well correlated to the texture of the cooked root; a higher starch concentration tends to result in a mealy texture (Nara 1957). It can be assumed that the concentration of starch remaining in the root after cooking must be very closely related to the texture. Since the maltose generation during heat cooking with heat results from starch degradation by amylolytic enzymes, it will significantly decrease the starch content and consequently induce the textural changes in the cooked storage root. However, there is little information about starch degradation regarding the texture of sweetpotatoes (Nara 1951, Walter et al. 1975). The starch degradation that occurs in storage roots during the storage period presumably induces textural changes in the cooked roots; however, there is also little information about the enzymic mechanism of starch degradation in the sweetpotato during the storage period (Takahata et al. 1995). Further investigation of the relationships between starch metabolism and the texture of steamed or baked sweetpotatoes in relation to storability is needed.

The amylose content will also influence the texture, although this content in the sweetpotato is lower than those of other roots and tuberous crops and has less variability compared with rice and wheat. The alteration of amylose content by conventional breeding techniques (Kitahara et al. 1996b) or by genetic transformation (Kimura et al. 2001) induced variations into the eating quality and the processability of sweetpotato storage roots.

The organoleptic characteristics such as the texture of cooked sweetpotatoes are also affected by other physical properties of the storage root tissues and cells. Relationships between the degree of disintegration of steamed tissues and the starch content in fresh raw tissues are recognized in sweetpotato storage roots (Nakamura et al. 2010, 2015) as well as in potatoes (Matsuura-Endo et al. 2002). The contents of pectic substances and concomitant $\mathrm{Ca}$ ions are also correlating factors of the degree of storage root tissue disintegration. Pectic substances, particularly chelating agentsoluble ones, play important roles together with divalent cations in cell adhesion in plant tissue (Grant et al. 1973). The treatment of storage root tissues of sweetpotatoes with chelating agents decreases their firmness in association with histological changes in the microstructure of the cell wall
(Fuchigami et al. 2002), and divalent cations are reported to have a preventive effect against the decrease in the firmness of potatoes (Ross et al. 2011). As for sweetpotatoes, the disintegration rate of steamed storage root tissues is correlated negatively with the contents per fresh weight of the chelating agent-soluble pectic fraction and calcium ions, which are divalent cations (Nakamura et al. 2015). Although other cell wall polysaccharides such as cellulose and hemicellulose in sweetpotato storage roots have been analyzed in terms of their chemical composition (Noda et al.1994), little information about their functions in the texture of cooked sweetpotato roots is available (Shen and Sterling 1981) and further investigations are still needed.

\section{Conclusion and future}

There is no doubt that the sweetpotato is an important crop not only as a staple food, but also as a supplier of starch raw materials. However, the lack of variations in its starch traits has prevented the demand for sweetpotatoes from expanding. Because of its high ploidy level, self-sterility, and crossincompatibility, it has been difficult to find useful mutants of sweetpotatoes. However, a ground-breaking variety for use in the manufacture of starch, Konamizuki (KM), was bred recently, and this variety has begun to spur new demand among food processing manufacturers. Moreover, progress in tissue culture and in the genetic transformation of the sweetpotato enables the production of various mutants by RNAimediated gene silencing. To date, several mutants related to starch pathways in the sweetpotato were produced artificially by RNAi methods as described in this review. Now, it has become possible to provide a wide range of amylose contents (0\% (GBSSI-RNAi), 10-20\% (non-transgenic), 26-29\% (SBEII-RNAi)) in sweetpotato starch.

Recently the importance of sweetness has risen to meet the needs of consumers in Japan. The varietal diversity in maltose production during the heating of sweetpotato storage roots has been well clarified over the past several decades. However, information on other free sugars, such as sucrose, fructose, and glucose, and on textural properties is still insufficient, as is our understanding of the changes in these components, including maltose, during the storage of sweetpotatoes. Further studies involving food-processing chemists and post-harvest physiologists are also needed.

The sweetpotato has not lent itself well to molecular breeding; however, the establishment of genetic transformation and the RNAi-mediated gene silencing method in this plant species has led to the creation of several useful mutants, and has made it comparable to other crops such as potatoes, rice, and maize. In addition, the draft genome sequence of $I$. trifida, the closest wild relative of the sweetpotato, has been reported (Hirakawa et al. 2015). We hope that several novel unique starches will be produced through marker-assisted and/or transgenic techniques in sweetpotato plants in the near future. Also, our research continues and we expect to further develop and discover novel sweetpotatoes 
with starches exhibiting distinct properties or sugars associated with attractive traits, thereby contributing to the promotion of sweetpotato utilization.

\section{Literature Cited}

Ai, Y. and J.-L. Jane (2015) Gelatinization and rheological properties of starch. Starch/Särke 67: 213-224.

Baba, T., H. Nakama, Y. Tamura and T. Yano (1987) Changes in sugar and starch contents during storage of new type sweet potato (low $\beta$-amylase activity in roots). J. Jpn. Soc. Food Sci. Tech. 34: 249 253.

BeMiller, J.N. (2007) Starches, Modified Food Starches, and Other Products from Starches. In: BeMiller,J.N. (ed.) Carbohydrate Chemistry for Food Scientists, 2nd edn. AACC International, Minnesota, pp. 173-223.

Bertoft,E. (2013) On the building block and backbone concepts of amylopectin structure. Cereal Chem. 90: 294-311.

Biliaderis, C.G. (2009) Structural transitions and related physical properties of starch. In: Bemiller, J. and R. Whistler (eds.) Starch Chemistry and Technology, Academic Press, New York, pp. 293-372.

Brown, I.L. (2004) Application and uses of resistant starch. J. AOAC Int. 87: 727-732.

Ceballos, H., T.Sánchez, N.Morante, M.Fregene, D. Dufour, A.M. Smith, K.Denyer, J.C.Pérez, F.Calle and C.Mestres (2007) Discovery of an amylose-free starch mutant in cassava (Manihot esculenta Crantz). J. Agric. Food Chem. 55: 7469-7476.

Edwards,A., D.C.Fulton, C.M.Hylton, S.A.Jobling, M.Gidley, U. Rössner, C. Martin and A.M. Smith (1999) A combined reduction in activity of starch synthase II and III of potato has novel effects on the starch tubers. Plant J. 17: 251-261.

Fuchigami, M., A. Teramoto and A. Sasaki (2002) Changes in firmness, pectic substances and histological structure of sweet potatoes during cooking, preheating or pressurization. J. Cookery Sci. Jpn. 35: 343-356.

Gidley, M.J. and P.V.Bulpin (1987) Crystallisation of maltooligosaccharides as models of the crystalline forms of starch: minimum chain-length requirement for the formation of double helices. Carbohydr. Res. 161: 291-300.

Grant, G.T., E.R. Morris, D.A. Rees, P.J.C. Smith and D. Thom (1973) Biological interactions between polysaccharides and divalent cations: the egg-box model. FEBS Lett. 32: 195-198.

Guan, H.P. and J. Preiss (1993) Differentiation of the properties of the branching isozymes from maize (Zea mays). Plant Physiol. 102: 1269-1273.

Hajdukiewicz, P., Z.Svab and P.Maliga (1994) The small versatile pPZP family of Agrobacterium binary vectors for plant transformation. Plant Mol. Biol. 25: 989-994.

Hanashiro, I., M. Tagawa, S. Shibahara, K. Iwata and Y. Takeda (2002) Examination of molar-based distribution of A, B and C chains of amylopectin by fluorescent labeling with 2-aminopyridine. Carbohydr. Res. 337: 1211-1215.

Hannah, L.C. and O.E. Nelson (1975) Characterization of adenosine diphosphate glucose pyrophosphorylases from developing maize seeds. Plant Physiol. 55: 297-302.

Hannah,L.C. and O.E. Nelson (1976) Characterization of ADPglucose pyrophosphorylase from shrunken-2 and brittle-2 mutants of maize. Biochem. Genet. 14: 547-560.

Hirakawa,H., Y. Okada, H.Tabuchi, K. Shirasawa, A. Watanabe, H. Tsuruoka, C. Minami, S. Nakayama, S. Sasamoto, M. Kohara et al. (2015) Survey of genome sequences in a wild sweet potato, Ipomoea trifida (H. B. K.) G. Don. DNA Res. 22: 171-179.

Hizukuri, S., J.Abe and I. Hanashiro (2006) Starch: Analytical Aspects. In: Eliasson, A.-C. (ed.) Carbohydrates in Food, 2nd edn. CRC Press, Taylor \& Francis, Boca Raton, pp. 305-390.

Hovenkamp-Hermelink, J.H.M., E. Jacobsen, A.S.Ponstein, R.G.F. Visser, G.H. Vos-Scheperkeuter，E.W.Bijmolt，J.N.de Vries，B. Witholt and W.J.Feenstra (1987) Isolation of an amylose-free starch mutant of the potato (Solanum tuberosum L.). Theor. Appl. Genet. 75: 217-221.

Hussain, H., A. Mant, R. Seale, S.Zeeman, E.Hinchliffe, A.Edwards, C. Hylton, S. Bornemann, A.M. Smith, C. Martin et al. (2003) Three isoforms of isoamylase contribute different catalytic properties for the debranching of potato glucans. Plant Cell 15: 133-149.

Ito, T., T.Ando and K. Ichikawa (1968) Effects of cooking processes on the saccharification of sweet potato (part 1): The relation between heating temperature and increase of sugar contents. J. Home Econ. Jpn. 19: 170-173.

Jobling, S.A., G.P. Schwall, R.J. Westcott, C.M. Sidebottom, M. Debet, M.J.Gidley, R. Jeffcoat and R. Safford (1999) A minor form of starch branching enzyme in potato (Solanum tuberosum L.) tubers has a major effect on starch structure: cloning and characterisation of multiple forms of SBE A. Plant J. 18: 163-171.

Katayama, K., K.Komae, K. Kohyama, T.Kato, S.Tamiya and K. Komaki (2002) New sweet potato line having low gelatinization temperature and altered starch structure. Starch/Särke 54: 51-57.

Katayama, K., S. Tamiya, T. Kuranouchi, K. Komaki and M. Nakatanni (2003) New sweet potato cultivar "Quick Sweet". Bull. NARO Inst. Crop Sci. 3: 35-52.

Katayama, K., S. Tamiya and K. Ishiguro (2004) Starch properties of new sweet potato lines having low pasting temperature. Starch/ Särke 56: 563-569.

Katayama, K., K. Kitahara, T. Sakai, Y.Kai and M. Yoshinaga (2011) Resistant and digestible starch contents in sweet potato cultivars and lines. J. Appl. Glycosci. 58: 53-59.

Katayama, K., T. Sakai, Y. Kai, Y. Nakazawa and M. Yoshinaga (2012) "Konamizuki": a new sweetpotato cultivar. Bull. NARO Kyushu Okinawa Agric. Res. Cent. 58: 15-36.

Katayama, K., S.Tamiya, T.Sakai, Y.Kai, A.Ohara-Takada, T. Kuranouchi and M. Yoshinaga (2015) Inheritance of low pasting temperature in sweetpotato starch and the dosage effect of wildtype alleles. Breed. Sci. 65: 352-356.

Kimura, T., M. Otani, T. Noda, O. Ideta, T. Shimada and A. Saito (2001) Absence of amylose in sweet potato (Ipomoea batatas (L.) Lam.) following the introduction of granule-bound starch synthase I cDNA. Plant Cell Rep. 20: 663-666.

Kitahara,K., Y.Ooi, S.Mizukami, S.Suganuma and T.Nagahama (1996a) Physicochemical properties of starches from sweetpotato cultivars. J. Appl. Glycosci. 43: 59-66.

Kitahara, K., S. Mizukami, T. Suganuma, T. Nagahama, M. Yoshinaga, T. Kumagai and O. Yamakawa (1996b) A new line of sweetpotato with a low amylose content. J. Appl. Glycosci. 43: 551-554.

Kitahara, K., J.Ueno, T. Suganuma, K. Ishiguro and O. Yamakawa (1999) Physicochemical properties of root starches from new types of sweetpotato. J. Appl. Glycosci. 46: 391-397.

Kitahara,K., Y.Takahata, M. Otani, M.Tanaka, K. Katayama, M. Yoshinaga, K. Fujita and T. Suganuma (2011) Starch properties of transgenic sweetpotato plants modified by RNA interference of the Starch Synthase II gene. J. Appl. Glycosci. 58: 85-90.

Kitahara, K., T. Yamasaki, K. Fujita and T. Suganuma (2014) Physicochemical properties of starches from recently bred sweetpotatoes in 
Japan. J. Appl. Glycosci. 61: 81-88.

Kuipers,A.G.J., E. Jacobsen and R.G.F. Visser (1994a) Formation and deposition of amylase in the potato tuber starch granule are affected by the reduction of granule-bound starch synthase gene expression. Plant Cell 6: 43-52.

Kuipers, A.G.J., W.J.J. Soppe, E. Jacobsen and R.G.F. Visser (1994b) Field evaluation of transgenic potato plants expressing an antisense granule-bound starch synthase gene: increase of the antisense effect during tuber growth. Plant Mol. Biol. 26: 1759-1773.

Kukimura, H., K. Komaki and M. Yoshinaga (1990) Current progress of sweetpotato breeding in Japan. JARQ 24: 169-174.

Kumagai, T., Y.Umemura, T.Baba and M. Iwanaga (1990) The inheritance of $\beta$-amylase null in storage roots of sweet potato, Ipomoea batatas (L.) Lam. Theor. Appl. Genet. 79: 369-376.

Kuranouchi, K., Y.Nakamura, A. Takada, S. Tamiya, M. Nakatani and T.Kumagai (2012) Breeding of a new sweetpotato variety "Hoshikirari" suitable for hoshi-imo steamed and cured slices with excellent quality. Bull. NARO Inst. Crop Sci. 13: 1-22.

Kuriki, T., D.C. Stewart and J.Preiss (1997) Construction of chimeric enzymes out of maize endosperm branching enzymes I and II: activity and properties. J. Biol. Chem. 272: 28999-29004.

Kuroda, M., M. Kimizu and C. Mikami (2010) A simple set of plasmids for the production of transgenic plants. Biosci. Biotechnol. Biochem. 74: 2348-2351.

Lloyd, J.R., V.Landschütze and J. Kossmann (1999) Simultaneous antisense inhibition of two starch-synthase isoforms in potato tubers leads to accumulation of grossly modified amylopectin. Biochem. J. 338: 515-521.

Martin, C. and A.M. Smith (1995) Starch biosynthesis. Plant Cell 7: 971-985.

Masuda,D., N.Fukuoka, H. Goto and Y.Kano (2007) Effect of cold treatment after harvest on sugar contents and storability in sweet potato (Ipomoea batatas L.). Hort. Res. (Japan) 6: 597-601.

Matsuura-Endo, C., A. Ohara-Takada, H. Yamauchi, Y.Mukasa, M. Mori and K. Ishibashi (2002) Disintegration differences in cooked potatoes from three Japanese cultivars: comparison of the properties of isolated starch, degree of cell separation with EDTA, and contents of calcium and galacturonic acid. Food Sci. Technol. Res. 8: 323-327.

Matsuura-Endo, C., A. Kobayashi, T. Noda, S. Takigawa, H. Yamauchi and M. Mori (2004) Changes in sugar content and activity of vacuolar acid invertase during low-temperature storage of potato tubers from six Japanese cultivars. J. Plant Res. 117: 131-137.

Matsuura-Endo,C., A. Ohara-Takada, Y.Chuda, H.Ono, H.Yada, M.Yoshida, A.Kobayashi, S.Tsuda, S.Takigawa, T.Noda, H. Yamauchi and M.Mori (2006) Effects of storage temperature on the contents of sugars and free amino acids in tubers from different potato cultivars and acrylamide in chips. Biosci. Biotechnol. Biochem. 70: 1173-1180.

Morell, M.K., B. Kosar-Hashemi, M. Cmiel, M.S. Samuel, P. Chandler, S. Rahman, A. Buleon, I.L. Batey and Z. Li (2003) Barley sex6 mutants lack starch synthase IIa activity and contain a starch with novel properties. Plant J. 34: 173-185.

Morrison, T.A., R.Pressey and S.J.Kays (1993) Changes in $\alpha$ - and $\beta$-amylase during storage of sweetpotato lines with varying starch hydrolysis potential. J. Am. Soc. Hortic. Sci. 118: 236-242.

Nakamura, Y. (1996) Some properties of starch debranching enzymes and their possible role in amylopectin biosynthesis. Plant Sci. 130: $1-18$.

Nakamura, Y., P.B.Francisco Jr., Y.Hosaka, A. Sato, T. Sawada, A. Kubo and N. Fujita (2005) Essential amino acids of starch syn- thase IIa differentiate amylopectin structure and starch quality between japonica and indica rice varieties. Plant Mol. Biol. 58: 213227.

Nakamura, Y., T. Kuranouchi, A.O. Takada, N.Ishida, I.Koda, N. Iwasawa, T.Matsuda and T. Kumagai (2010) Cell structure, water status and starch properties in tuberous root tissue in relation to the texture of steamed sweetpotato (Ipomoea batatas (L.) Lam). Jpn. J. Crop Sci. 79: 284-295.

Nakamura, Y., A.O.Takada, T.Kuranouchi, R. Masuda and K. Katayama (2014a) Mechanism for maltose generation by heating in the storage roots of sweet potato cultivar 'Quick Sweet' containing starch with a low pasting temperature. J. Jpn. Soc. Food Sci. Tech. 61: 62-69.

Nakamura, Y., T.Kuranouchi, A.O.Takada and K. Katayama (2014b) The effects of $\beta$-amylase activity and starch pasting temperature on maltose generation in steamed storage roots of sweet potato. J. Jpn. Soc. Food Sci. Tech. 61: 577-585.

Nakamura, Y., A.O.Takada, T.Kuranouchi and K. Katayama (2015) Disintegration of steamed root tissues of sweet potato and its relation to texture and the contents of starch, calcium and pectic substances. J. Jpn. Soc. Food Sci. Tech. 62: 555-562.

Nara, S. (1951) Few fundamental studies on utilization and storage of sweet potato. Bull. Fac. Educ. Mie Univ. 6: 31-37.

Nara, S. (1957) On the steamed sweet potato product-on the differences of mealiness and sojjiness. Bull. Fac. Agric. Mie Univ. 14: 145-147.

Nestel, P.J., M. Noakes, P.Clifton and G. Mclntosh (1996) High amylose starch on bowel function, insulin sensitivity and lipids. FASEB J. 10: 3168 .

Noda, T., Y. Takahata, T. Nagata and N. Shibuya (1994) Chemical composition of cell wall material from sweet potato starch residue. Starch/Stärke 46: 232-236.

Noda, T., Y.Takahata, T. Sato, I. Suda, T.Morishita, K. Ishiguro and O. Yamakawa (1998) Relationships between chain length distribution of amylopectin and gelatinization properties within the same botanical origin for sweet potato and buckwheat. Carbohydr. Polym. 37: 153-158.

Noda,T., T. Kobayashi and I. Suda (2001) Effect of soil temperature on starch properties of sweet potatoes. Carbohydr. Polym. 44: 239246.

Otani, M. and T. Shimada (1996) Efficient embryogenic callus formation in sweet potato (Ipomoea batatas (L.) Lam.). Breed. Sci. 46: 275-280.

Otani, M., T. Shimada, T. Kimura and A. Saito (1998) Transgenic plant production from embryogenic callus of sweet potato (Ipomoea batatas (L.) Lam.) using Agrobacterium tumefaciens. Plant Biotechnol. 15: 11-16.

Otani, M., T. Hamada, K. Katayama, K. Kitahara, S.H. Kim, Y. Takahata, T. Suganuma and T. Shimada (2007) Inhibition of the gene expression for granule-bound starch synthase I by RNA interference in sweet potato plants. Plant Cell Rep. 26: 1801-1807.

Pan,D. and O.E. Nelson (1984) A debranching enzyme deficiency in endosperms of the sugary-1 mutants of maize. Plant Physiol. 74: 324-328.

Pérez, E., O. Gibert, A. Rolland-Sabaté, Y. Jiénez, T. Sánchez, A. Giraldo, B. Pontoire, S. Guilois, M.-C. Lahon, M. Reynes et al. (2011) Physicochemical, functional, and macromolecular properties of waxy yam starches discovered from "Mamuey" (Dioscorea trifida) genotypes in the Venezuelan Amazon. J. Agric. Food Chem. 59: 263273.

Pérez, S. and E.Bertoft (2010) The molecular structures of starch 
components and their contribution to the architecture of starch granules: A comprehensive review. Starch/Stärke 62: 389-420.

Pfannemüller, B. (1987) Influence of chain length of short monodisperse amyloses on the formation of A- and B-type X-ray diffraction patterns. Int. J. Biol. Macromol. 9: 105-108.

Picha, D.H. (1986a) HPLC determination of sugars in raw and baked sweet potatoes. J. Food Sci. 50: 1189-1190.

Picha,D.H. (1986b) Carbohydrate changes in sweet potatoes during curing and storage. J. Am. Soc. Hortic. Sci. 111: 889-892.

Picha,D.H. (1987) Chilling injury, respiration and sugar changes in sweet potatoes stored at low temperature. J. Am. Soc. Hortic. Sci. 112: 497-502.

Preiss, J. (1996) ADPglucose pyrophosphorylase: basic science and applications in biotechnology. Biotechnol. Annu. Rev. 2: 259-279.

Regina,A., A.Bird, D. Topping, S.Bowden, J.Freeman, T. Barsby, B. Kosar-Hashemi, Z.Li, S. Rahman and M. Morell (2006) Highamylose wheat generated by RNA interference improves indices of large-bowel health in rats. Proc. Natl. Acad. Sci. USA 103: 35463551.

Ross, H.A., K.M. Wright, G.J. McDougall, A.G. Roberts, S.N. Chapman, W.L.Morris, R.D.Hancock, D.Stewart, G.A.Tucker, E.K. James et al. (2011) Potato tuber pectin structure is influenced by pectin methyl esterase activity and impacts on cooked potato texture. J. Exp. Bot. 62: 371-381.

Schwall, G.P., R. Safford, R.J. Westcott, R. Jeffcoat, A. Tayal, Y.C.Shi, M.J.Gidley and S.A.Jobling (2000) Production of very-highamylose potato starch by inhibition of SBE A and B. Nat. Biotechnol. 18: 551-554.

Shen, M.C. and C. Sterling (1981) Changes in starch and other carbohydrates in baking Ipomoea batatas. Starch/Särke 33: 261-268.

Shimada,H., Y.Tada, T.Kawasaki and T.Fujimura (1993) Antisense regulation of the rice waxy gene expression using a PCR-amplified fragment of the rice genome reduces the amylose content in grain starch. Theor. Appl. Genet. 86: 665-672.

Shimada, T., M.Otani, T.Hamada and S.H.Kim (2006) Increase of amylose content of sweetpotato starch by RNA interference of the starch branching enzyme II gene (IbSBEII). Plant Biotechnol. 23: 85-90.

Srichuwong, S., T. Orikasa, J.Matsuki, T.Shiina, T.Kobayashi and K. Tokuyasu (2012) Sweet potato having a low temperaturegelatinization starch as a promising feedstock for bioethanol production. Biomass Bioenergy 39: 120-127.

Suganuma, T., S. Fujimoto, K. Kitahara and T. Nagahama (1996) Classification of starches from wild plants in Japan by cluster analysis and their visualization by radar chart. J. Appl. Glycosci. 43: 525533.

Takahata, Y., T. Noda and T.Nagata (1992) Varietal diversity of free sugar composition in storage root of sweet potato. Jpn. J. Breed. 42: 515-521.

Takahata, Y., T. Noda and T. Nagata (1994) Effect of $\beta$-amylase stability and starch gelatinization during heating on varietal differences in maltose content in sweetpotatoes. J. Agric. Food Chem. 42: 2564-2569.

Takahata, Y., T. Noda and T. Sato (1995) Changes in carbohydrates and enzyme activities of sweetpotato lines during storage. J. Agric. Food Chem. 43: 1923-1928.

Takahata, Y., T. Noda and T. Sato (1996) Relationship between acid invertase activity and hexose content in sweet potato storage roots. J. Agric. Food Chem. 44: 2063-2066.

Takahata,Y., M. Tanaka, M. Otani, K. Katayama, K. Kitahara, O. Nakayachi, H. Nakayama and M. Yoshinaga (2010) Inhibition of the expression of the starch synthase II gene leads to lower pasting temperature in sweetpotato starch. Plant Cell Rep. 29: 535-543.

Takeda, Y., H.P. Guan and J. Preiss (1993) Branching of amylose by the branching isoenzymes of maize endosperm. Carbohydr. Res. 240: 253-263.

Tetlow, I.J. (2011) Starch biosynthesis in developing seeds. Seed Sci. Res. 21: 5-32.

Tokimura, K., H. Shimozono, K. Ikeda and H. Tanoue (2002) The retrogradation of starch gels and starch properties from various kinds of sweet potato starches. J. Appl. Glycosci. 49: 305-312.

Umemoto, T., M. Yano, H. Satoh, A. Shomura and Y. Nakamura (2002) Mapping of a gene responsible for the difference in amylopectin structure between japonica-type and indica-type rice varieties. Theor. Appl. Genet. 104: 1-8.

Vamadevan, V. and E. Bertoft (2015) Structure-function relationships of starch components. Starch/Särke 67: 55-68.

Visser, R.G.F., I. Somhorst, G.J. Kuipers, N.J. Ruys, W.J.Feenstra and E. Jacobson (1991) Inhibition of the expression of the gene for granule bound starch synthase in potato by antisense constructs. Mol. Gen. Genet. 225: 289-296.

Walter, Jr. W.M., A. Purcell and A.M. Nelson (1975) Effects of amylolytic enzymes on "moisture" and carbohydrate changes of baked sweet potato cultivars. J. Food Sci. 40: 793-796.

Walter, Jr. W.M. (1987) Effect of curing on sensory properties and carbohydrate composition of baked sweet potatoes. J. Food Sci. 52: 1026-1029.

Waterhouse, P.M., M.W. Graham and M.B.Wang (1998) Virus resistance and gene silencing in plants can be induced by simultaneous expression of sense and antisense RNA. Proc. Natl. Acad. Sci. USA 23: 13959-13964.

Yamamori, M., S. Fujita, K. Hayakawa, J. Matsuki and T. Yasui (2000) Genetic elimination of a starch granule protein, SGP-1, of wheat generates an altered starch with apparent high amylose. Theor. Appl. Genet. 101: 21-29.

Zhang, X., C.Colleoni, V. Ratushna, M.Sirghie-Colleoni, M.G. James and A.M.Myers (2004) Molecular characterization demonstrates that the Zea mays gene sugary 2 codes for the starch synthase isoform SSIIa. Plant Mol. Biol. 54: 865-879.

Zhu,F. and S. Wang (2014) Physicochemical properties, molecular structure, and uses of sweetpotato starch. Trends Food Sci. Technol. 36: 68-78. 